\title{
Titanium and Technological Problems of Its Machining
}

Karol Vasilko

Faculty of Manufacturing Technology Technical university of Košice with the seat in Prešov. karol.vasilko@tuke.sk

Titanium is considered to be the metal of the 21 st century . A material which has small density (at least two-three times smaller than iron), plasticity, shapeability, high resistance, rigidity and longevity has been required for a long time. It is required not to loose those features at high temperatures, be non-degradable in air, river and sea water, not to be soluble in acides and lyes; at the same time, it requires to have sufficient amount in terrestrial crust. Titanium is such a material. Due to its specific qualities, its applications have been spreading into many areas such as medicine (implants), space (material for space technology), chemical facilities, ships for marine transport (resistance to acids and salts), wall hooks for climbers (low density and high rigidity), ... However, titanium mechanical features lead to new problems during its technological machining. It is necessary to apply considerably different approach in its cutting. During cutting, titanium and its alloys behave specifically and it is important to know this behaviour and use it for effective part production.

Keywords: machining, titanium alloys, turning, grinding

\section{Titanium characteristics}

Titanium possesses ordinal number 22 in Mendeleev's period table. Its neutral atom consists of a nucleus containing 22 protons and a set of 22 electrons. The number of neutrons ranges from 24 to 28 . This is the reason why the number of titanium isotope differs. Titanium can be enriched with some metals which increase its durability by ten- to thousand-times. For instance, they are $\mathrm{Zr}$, $\mathrm{Ha}, \mathrm{Ta}, \mathrm{W}$. By adding 20-30\% Mo, titanium corrosive stability similar to the one of gold can be obtained. Titanium is difficult to smelt. The temperature of pure titanium smelting is the highest of all construction materials: $1668^{\circ} \mathrm{C}$. Titanium has high tenacity and this is the reason why it is well resistant to cavitation. It is a suitable material for screw-propellers. It has a special feature - shape memory. In the alloy with some metals, for instance nickel, it remembers the shape of the part which has been produced at certain temperature. For example, if a spring is turned from the material in hot state, during heating to the temperature at which it has been produced, it returns to the original shape. This is used in space (opening of previously folded antenas), medicine (a wire is lead into stenotic vessel which coils into a spring at the body temperature and spreads the vessel). Titanium has small heat conductivity $\left(\lambda=0.071 \mathrm{~J} \cdot \mathrm{cm}^{-1} \cdot \mathrm{s}^{-1} \cdot{ }^{0} \mathrm{C}^{-1}\right)$ which is three-times smaller than the iron one's. The linear heat conductivity coefficient at room temperature is $8.5 \times 10^{-6} .{ }^{0} \mathrm{C}^{-1}$. The electric conductivity at room temperature is $42.1 \times 10^{-6} \Omega$ . $\mathrm{cm}$. It is a typical paramagnetics. However, it also has some negative features. It is prone to self-ignition, and is combustible in some cases. In the form of a delicate chip or powder it can ignite even without air supply. Titanium preserves its mechanical features up to high temperatures $\left(400-500^{\circ} \mathrm{C}\right)$. It is not damaged up to the temperature $235^{\circ} \mathrm{C}$. It belongs among light metals. Its density is 4.517 g. $\mathrm{cm}^{-3}$. It means it is 1.4-times heavier than aluminium and 1.5-times lighter than iron. However it does not predecede them in rigidity. At higher temperatures it absorbs gases, mainly oxygen and nitrogen by which its plasticity decreases and its rigidity and hardness grow (this is used in blades of gas turbines) [5]. Pure titanium is rigid, hard, tough plastic metal. Its $H B$ is around $1000 \mathrm{MN} . \mathrm{m}^{-2}, E=$ 108 tis.MN.m ${ }^{-2}, R_{\mathrm{e}}=250 \mathrm{MN} \cdot \mathrm{m}^{-2}$. It has the biggest friction coefficient from all metals therefore it is not suitable for parts which are in friction contact with other parts (leads, friction bearings).

\section{Problems of titanium machining}

Machining is harder due to titanium high friction coefficient. Titanium sticks to tool working areas. There is practically no slide of chip along the tool face. The area of contact of the chip with tool face is very small. Great pressures and temperatures occur on this area. Heat abstraction is hindered due to titanium small heat conductivity. Sticking of titanium elements on tool changes its geometry and quickly loses its ability to machine. Diamond, which has the smallest friction coefficient among cutting materials, is a suitable tool material.

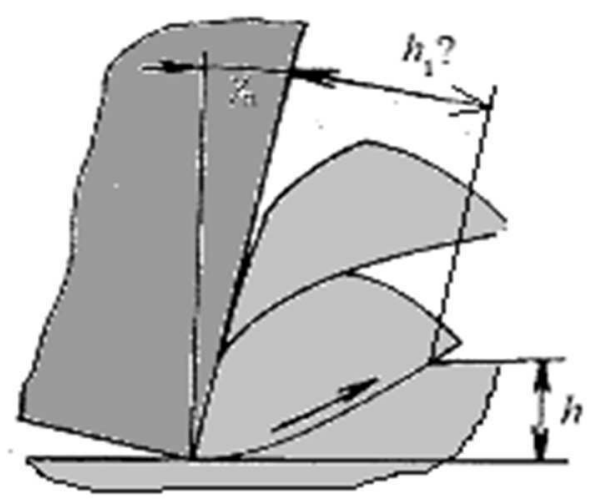

Fig. 1 Mechanism of chip creation for titanium machining

Titanium and its alloys rank among materials which are difficult to machine. Character of machining differs greatly from machining of other metal materials. Tool durability is very small as a result of the deformation of cutting wedge and the increase of the radius of cutting edge rounding. Heat concentrates into a narrow area in 
tool cutting wedge because titanium small heat conductivity hinders heat abstraction into the chip and workpiece. On the other hand, cutting forces and consummed performance is considerably smaller than when steel is machined. The problem is based on the fact that the chip is not smooth but consists of elements which are created as a result of high friction coefficient between tool and cut materials [7], [8]. The chip does not leave along the tool face but upwards and creates segments as a result of periodic slides in material (Fig. 1).

Gradual compression of creating chip segment pushes the segment up. The contact between the created segment and a new one gradually moves as a result of straightening teh segment away from the tool side. The speed of chip movement along the tool face will be equal to the speed of chip element compression. Because the slide has been created and spreads quickly it will move the creating element in the direction paralelly with the area of slide. This must basically speed up shifting of the element. This part of a cycle which is distinct by the segment movement along the tool face has periodic break-offs which are characterisedby the fact that minimal force is necessary for the segment to be compressed.

In Fig. 2 there is a photograph of creating chip [11].

It can be seen that the intensity of plastic deformation in the chip is greatly variable. In the center of elements there is little deformed structure, ammong segments there occurs periodic adiabatic slide. Chip segmentation is probably linked with unstable character of deformation which is conditioned by mutual influence of two mechanisms.

- Decrease of rigidity influenced by the heat of friction and deformation

- Deformation reinforcement

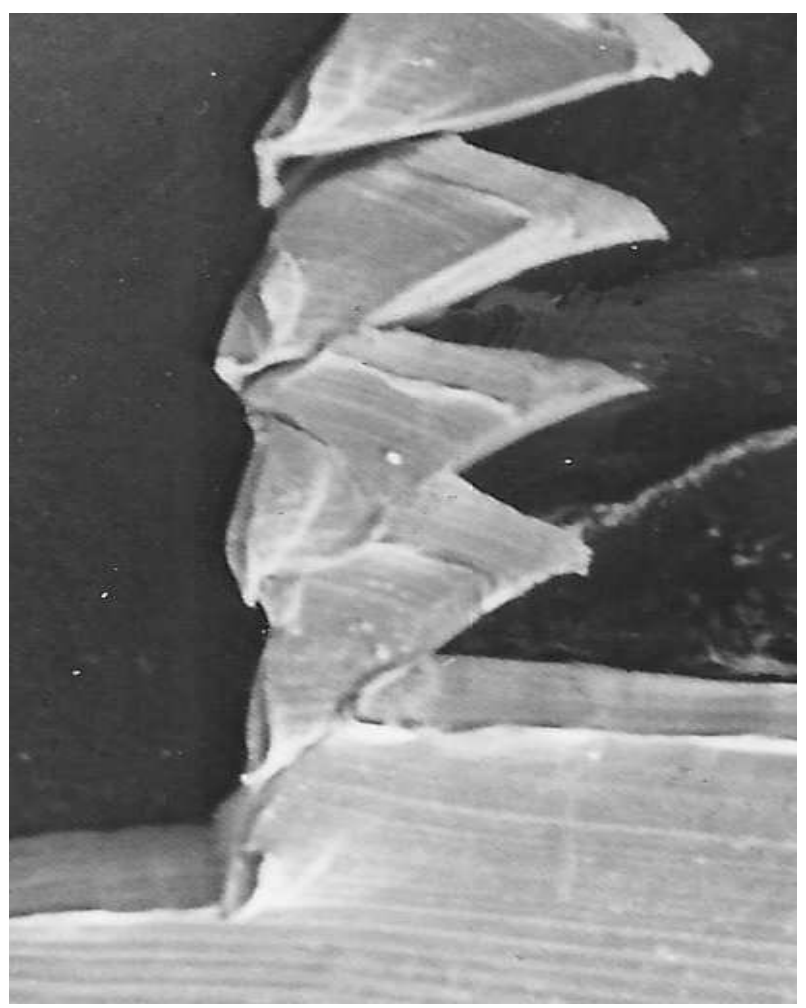

a)

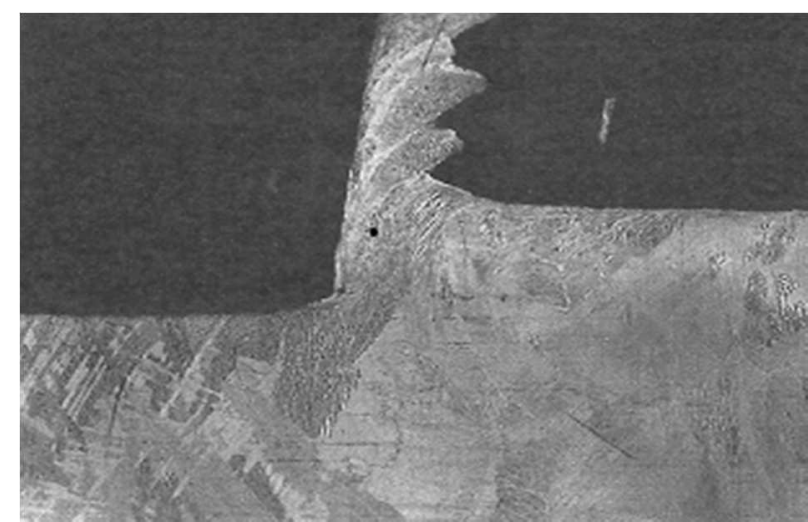

b)

Fig. 2 Creation of titanium chip, a-view, b-metallographic thin section

Creation of stripes of concentrated slide is connected with material bad heat conductivity. Observation of chip creation by speed camera has shown alternating break off of chip movement the reason of which could be welded connections of chip and tool. This explains high intesiveness of tool wear.

Great slide can be seen on segment borders. Considerable deformation can be seen on the rear side of the chip which was transition area of workpiece before - Fig. 3 . As it can be seen, there often occurs complete separation of different chip elements.

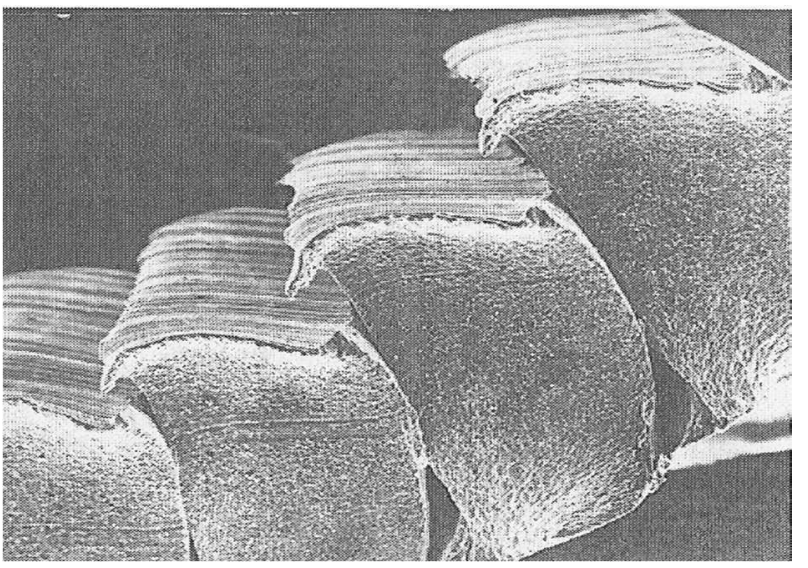

Fig. 3 Photography of titanium chip from line microscope

Positive aspect is the fact that when titanium is machined there is no problem with chip shaping. The chip is elementary, not very compact and falls apart when it hits an obstruction. Chip shaper is not necessary on the tool. Negative effect of the described mechanism of chip creation is self-initiated tool oscillation.

The graduality of phenomena when segmented chip is created can be divided into two stages.

- In the first phase, plastic instability is recorded which leads to the localisation of deformation along the area of sliding. This area starts on the cutting edge and first it is oriented in the direction of cutting speed vector, next it bends up where it crosses the cut area. Slide disruption of 
the chip appears on its outer side in a form of fissures and on the inner side in a form of heavily deformed stripes.

- In the second phase, gradual straightening / smoothing of semi-wedge (inclined side of chip segment) oriented towards cut material as a result of tool relocation. As a result of this, chip thickness will approximately equal the thickness of cut-off layer.

This lead several authors to misinterpretation that when titanium is machined, there is a large angle of the border of primary plastic deformation. It means that chip compression should equal 1 , which is in contradiction with the laws of plastic deformation (content conservation law). The use of term „slide angle“ does not suit this case. The process of deformation in this narrow stripe is very probably an adiabatic slide. The disruption occurs as a result of compression from bordering metal layers (a case of areal deformation). Alongside the chip, the material is free and not held by anything (areal voltage state), which allows the segment to spread and create fissures.

In this connection there occurs a question how to evaluate the parameter of chip compression in this case. Classical process is based on measuring the thickness of cutoff layer and the chip thickness according to Fig. 1 . However, value $h_{1}$ is argumentative. Chip thickenss cannot be identifed by geometric measurement ( $h_{\mathrm{t}}$ from Fig. 1 is just estimated value). It is necessary to use the following procedure. The caught chip of certain lenght and known density of cut material is considered, by counting mean chip compression from the following equation:

$$
k=\frac{100 \cdot m_{\mathrm{t}}}{l_{\mathrm{t}} \cdot \gamma \cdot S}
$$

where:

$m_{\mathrm{t}}$ is chip weight, length $l_{\mathrm{t}}, \mathrm{g}$

$S$ - cut cross-section area $\left(a_{\mathrm{p}} \mathrm{x} f\right), \mathrm{mm}^{2}$

$l_{\mathrm{t}}$ - caught chipt length, mm

$\gamma$ - cut material density, g. $\mathrm{mm}^{-3}$

\section{Some experimental results}

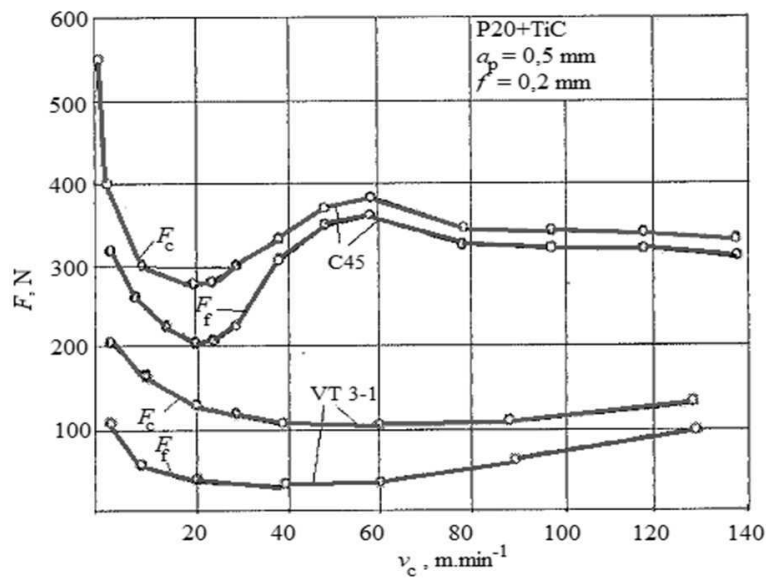

Fig. 4 Experimental dependence of cutting force on cutting speed when turning titanium and steel
Frequent titanium alloy VT 3-1 $(5,5-7 \% \mathrm{Al} ; 2-3 \% \mathrm{Mo}$; $1-2,5 \% \mathrm{Cr} ; 0,15-0,4 \% \mathrm{Si} ; 0,2-0,7 \% \mathrm{Fe})$ has been used in experimental turning.

As it has been presented, cutting forces are smaller than the ones working during steel turning in spite of higher titanium rigidity. In Fig. 4 there is an experimental dependence of cutting forces on cutting speed for both observed materials.

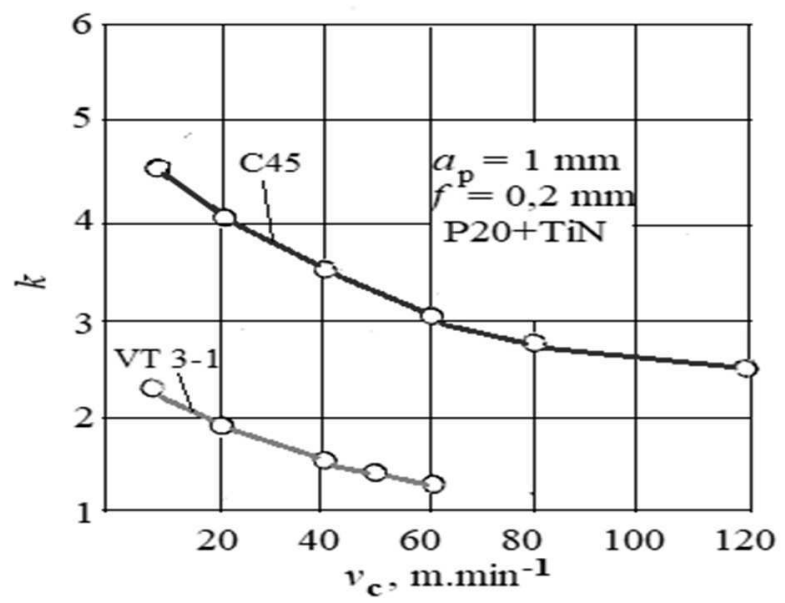

Fig. 5 Experimental dependence of chip compression on cutting speed for steel C45 and titanium alloy VT 3-1

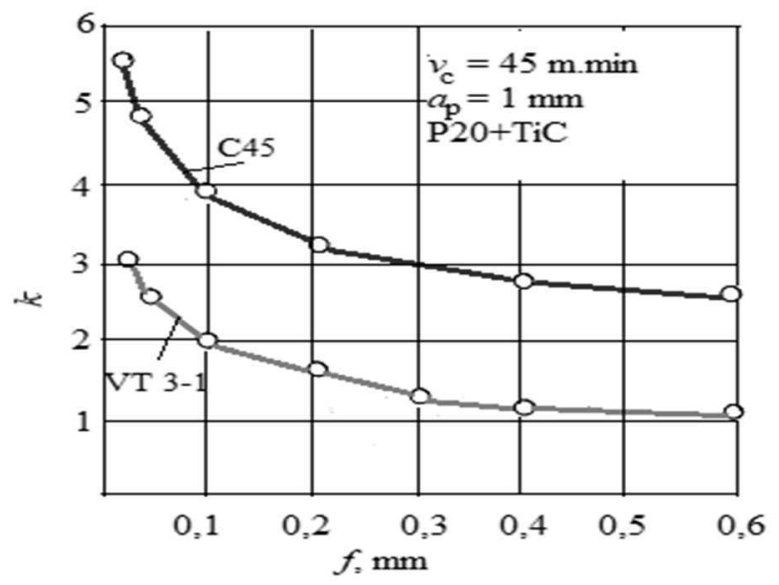

Fig. 6 Experimental dependence of chip compression on shift for observed materials

In whole range of observed cutting steels, cutting forces are considerably smaller for titanium turning. While for steel minimum force can be identified approximately at cutting speed $20 \mathrm{~m} \cdot \mathrm{min}^{-1}$ and maximum at cutting speed, in given case, cca $60 \mathrm{~m} \cdot \mathrm{min}^{-1}$, titanium behaves completely differently. Cutting force continually decreases up to the cutting speed $60 \mathrm{~m} \cdot \mathrm{min}^{-1}$, then it slightly increases.

Chip compression depending on cutting speed evalutated with the use of equation (1) is shown in Fig. 5.

As it can be seen, the course of both dependences is dissimilar. It approaches 1 at higher cutting speed for titanium. It is given by the mechanism of creating elements where regular adiabatic slides occur while in the center of elements, material is deformed minimally (Fig. 2).

Depending on the shift for both materials, the course is different in absolute values but it continually decreases (Fig. 6). 
Specific mechanical features of titanium are conditioned also by the mechanism of tool wear. In Fig. 7 there are experimental curves of dependences of tool wear on back depending on machining time and cutting speed obtained during turning of titanium alloy VT 3-1 by the tool of sintered carbid $\mathrm{P} 20$ with coating TiC.

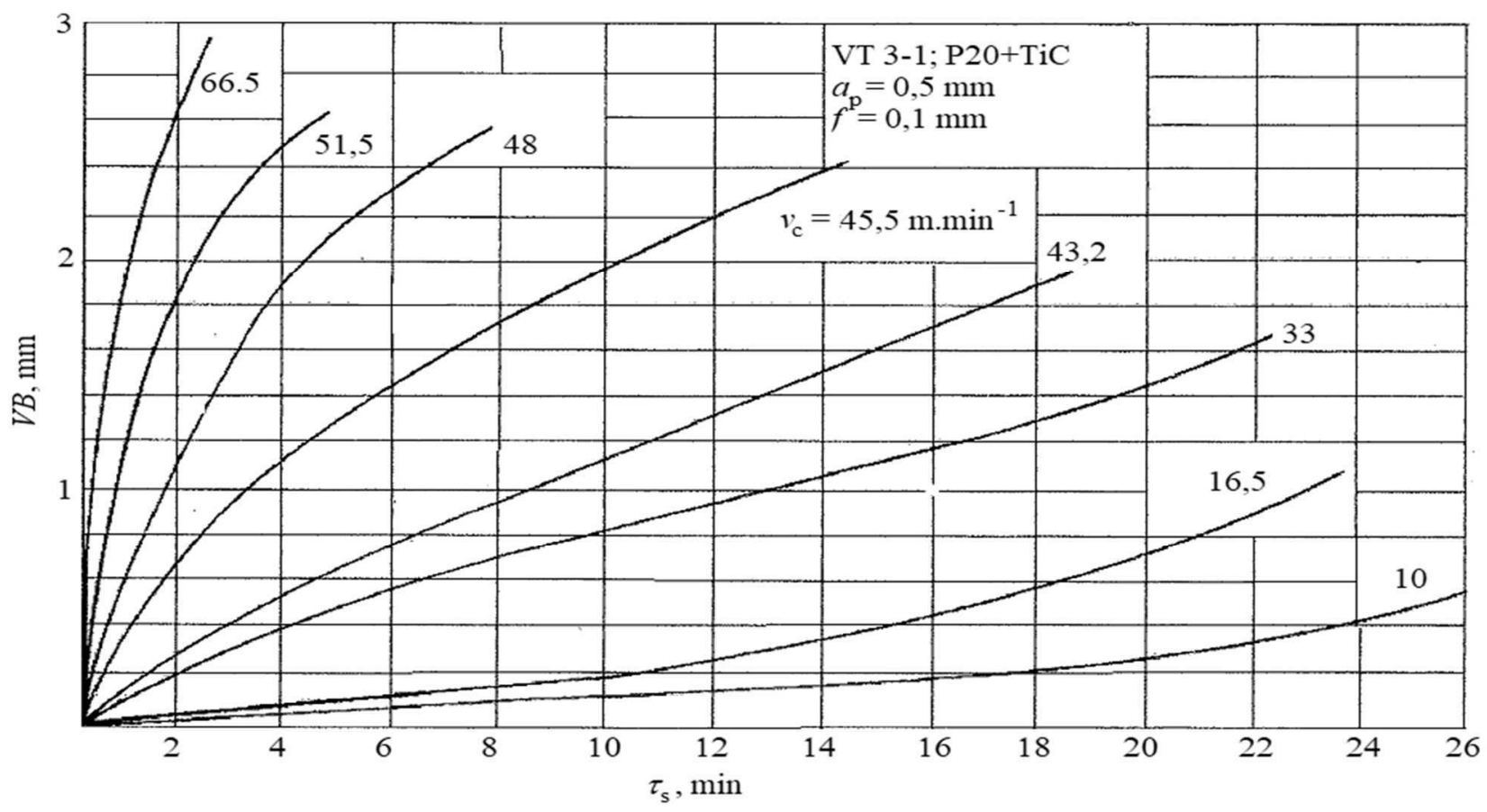

Fig. 7 Experimental curves of dependence $V B-\tau_{s}$

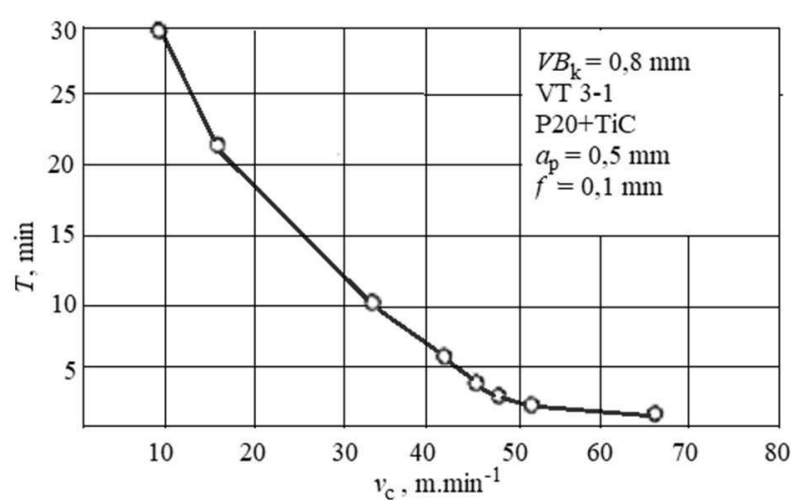

Fig. 8 Experimental dependence of tool durability on cutting speed

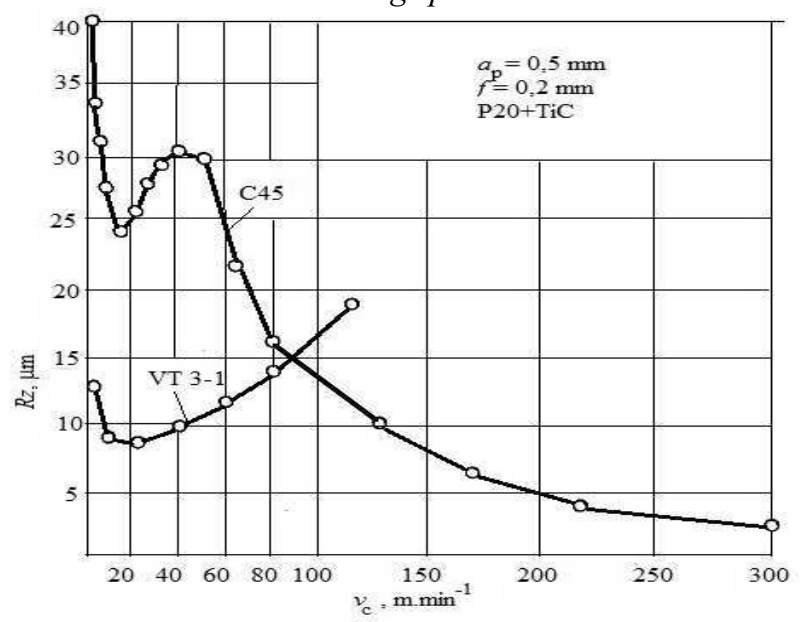

Fig. 9 Experimental dependence of the highest height of uneveness of machined surface on cutting speed when machining steel C45 and titanium alloy $\left(r_{\varepsilon}=0.8 \mathrm{~mm}\right)$.

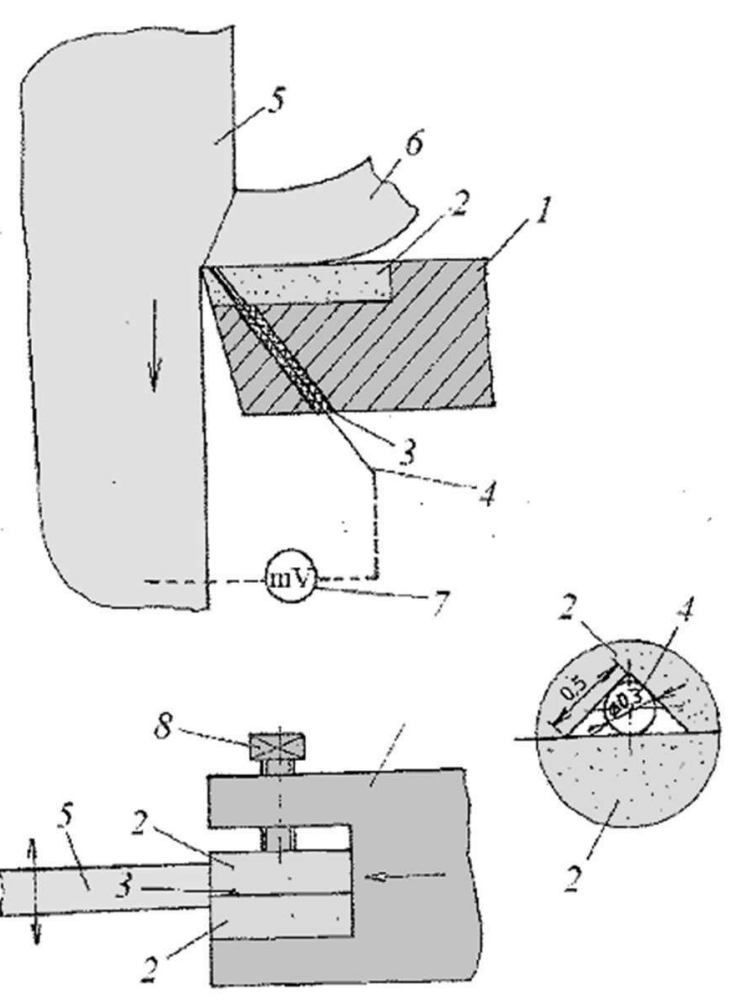

Fig. 10 Measuring of contact temperature between the chip and tool face. 1-tool, 2-ceramic cutting plate, 3-insulation, 4-platinum wire, 5-workpiece, 6-chip, 7-milivoltmeter, 8 -clamping screw.

As it can be seen, the intensiveness of tool wear grows sharply with growing cutting speed. It can more demonstratively be seen on dependence $T-v_{\mathrm{c}}$, obtained from Fig. 
5 with blunting criterion $V B_{\mathrm{k}}=0.8 \mathrm{~mm}$, in Fig. 8 .

It is a typical hyperbolic dependence, it documents much smaller tool durability than at steel machining in the whole range of these cutting speeds. It is followed by the inadvisability of higher cutting speed than $60 \mathrm{~m} . \mathrm{min}^{-}$ ${ }^{1}$. A general rule for the selection of cutting speed can be presented; it should approximately be one-tenth of the one for machinig steel $\left(v_{\mathrm{cti}}=0,1 . v_{\mathrm{cFe}}\right)$ for the same used cutting material.

Quality of machined surface is an important parameter of titanium cutting [2] [8], [10]. In Fig. 9 there is an experimental diagramme of dependence $R z-v_{\mathrm{c}}$.

The course of dependence is considerably different from steel turning. At minimal cutting speeds, $R z$ grows for both steel and titanium as a result of fissure-making process of chip creation. Similarly to steel, it reaches minimum cutting speeds around $20 \mathrm{~m} \cdot \mathrm{min}^{-1}$. With the increase of cutting speed over $20 \mathrm{~m} \cdot \mathrm{min}^{-1} R z$ continually worsens when titanium is cut. Cutting speed higher than
$60 \mathrm{~m} \cdot \mathrm{min}^{-1}$ is not suitable for titanium machining. The experiment could be conducted at higher cutting speed only in the course of several seconds because there occurs spontaneous tool wear [12]. In whole range of cutting speeds up to $60 \mathrm{~m} \cdot \mathrm{min}^{-1}$ the quality of machined surface of titanium is much better than the one of steel. After that, however, it crosses it up to the value of $90 \mathrm{~m} \cdot \mathrm{min}^{-1}$.

In this phase of tests, the temperature of the contact between the tool and the chip has been compared. To observe actual temperatures, the principle according to Fig. 10 has been applied.

Two ceramic plates 2 are clamped in the tool holder 1 with a screw. One of them has a groove grinded in and a platinum wire 4 is inserted into it. When the wire touches the chip, milivoltmeter immediately records the value of thermoelectric force between the chip and the tool face. The change of temperature in cross direction can be recorded by a cross shift ot the tool against the workpiece. In polongitudinal direction, the temperature is recorded after the exchange of grinded out plate with a different groove position.

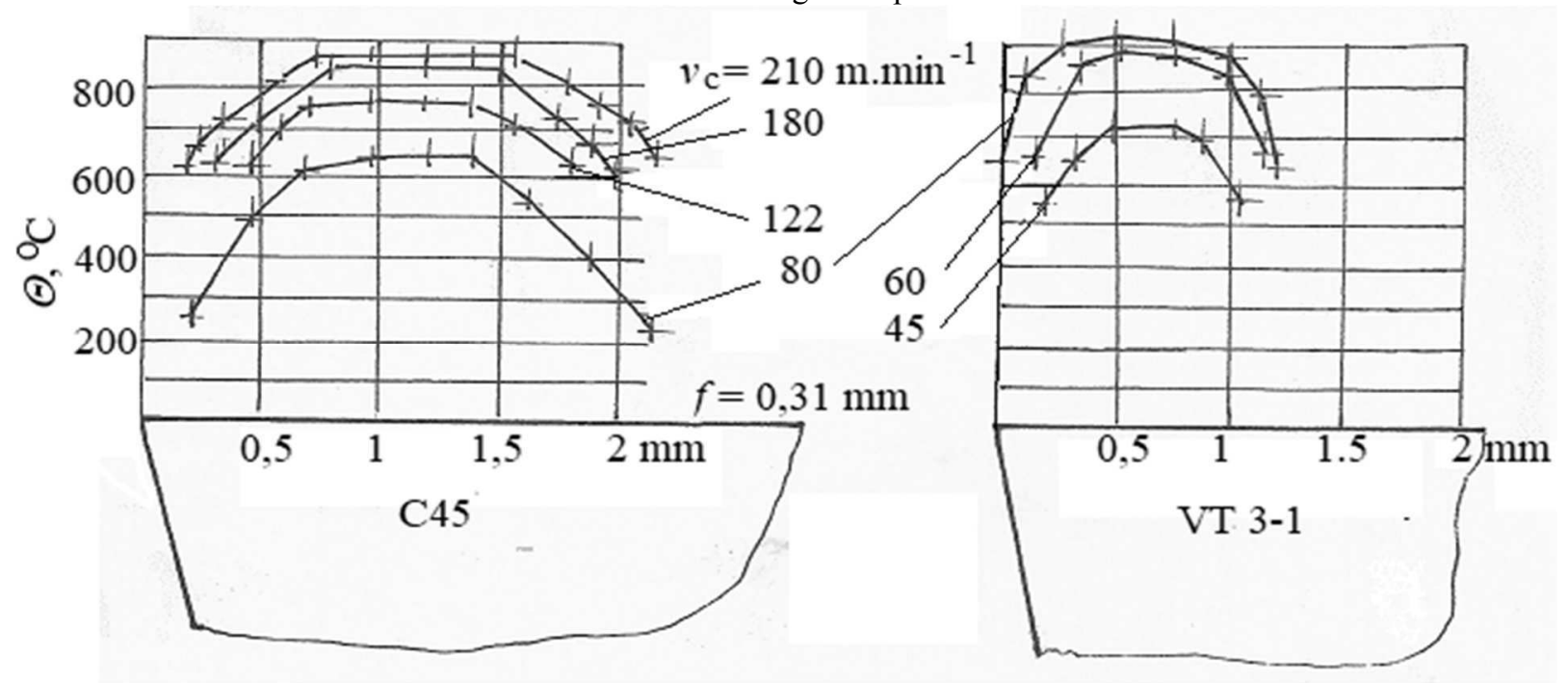

a)

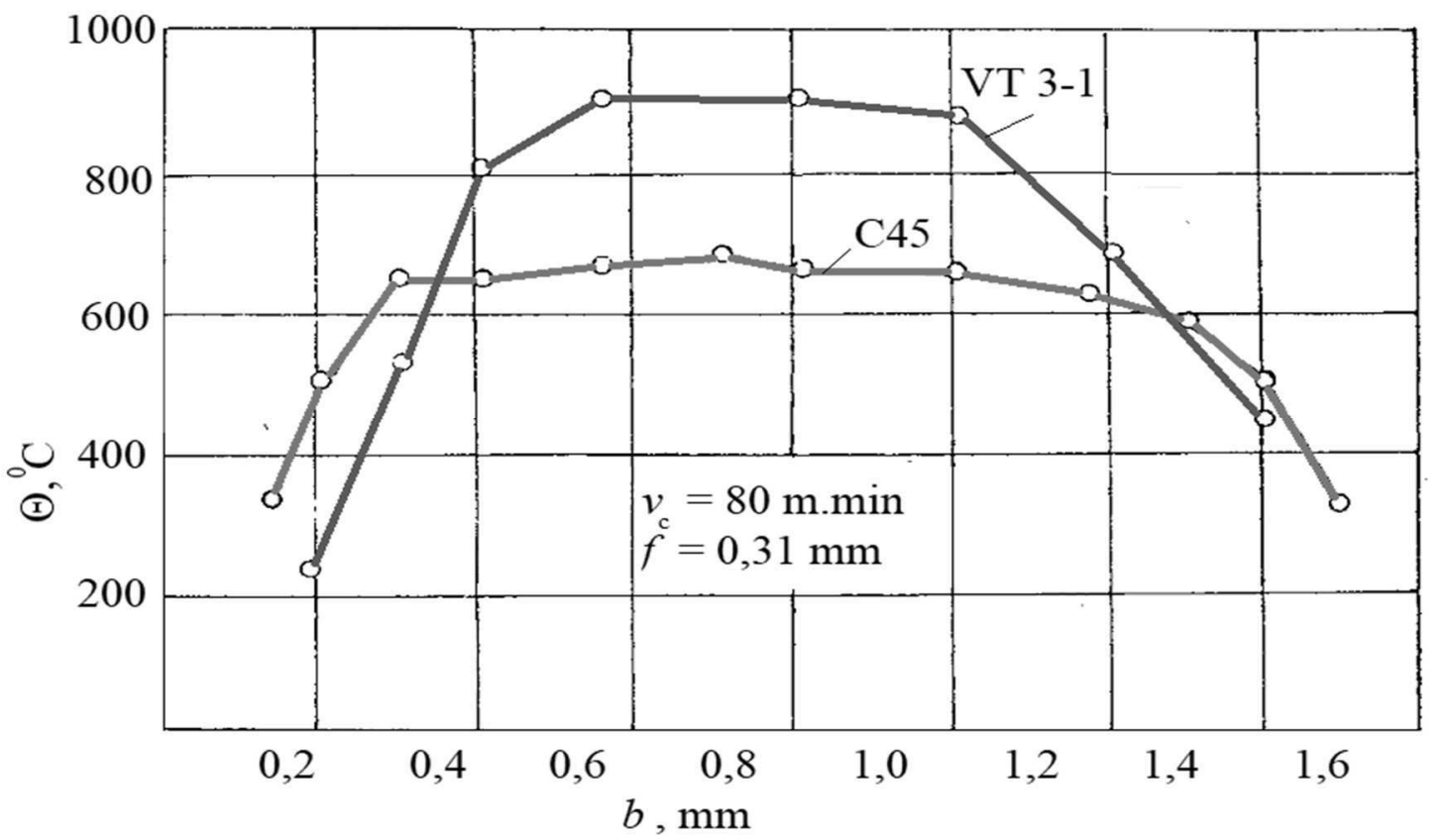

Fig. 11 Course of temperatures on tool face for steel and titanium machining in two planes, a-radial, b-axial 
The result of measurement is shown in Fig. 11.

As it can be seen, when titanium is machined, the length of contact of a chip and tool face is much shorter. At the same cutting speeds, the temperature of contact is much higher than the one for steel. Both these facts lead to higher heat wear of the cutting wedge and by this to the decrease of tool durability. Wear is shown in plastic rounding of the cutting wedge and the growth of radius $r_{\mathrm{n}}$. This is why soldered tools must often be sharpened when titanium is machined. By coating the tools, $r_{\mathrm{n}}$ grows which has negative effect when titanium is cut.

\section{Conclusion}

It is obvious that titanium and its alloys applications will spread into different applications in mechanical engineering, chemical, food-processing, aviation and space industries. Therefore knowing the conditions of economical machining of this material is important. Physical mechanical and chemical titanium features predestine it for light and rigid constructions. However, it causes considerable difficulties in its technological processing. Mainly its high rigidity causes that higher cutting speeds cannot be applied. Low heat conductivity causes that during cutting, heat is not conducted into the chip or workpiece. It concentrates in the cutting wedge and causes it degradation, after short machining time. It is important that the cutting wedge is sharp at all times with minimal radius of cutting edge rounding. This is the reason why the economical durability of the cutting edge much smaller than the one for steel machining. High friction coefficient of titanium with any other metal, i.e. also with tool material, causes problems in chip creation and machined surface. Due to adhesive connection it is not advisable to use cutting tools which contain titanium. The chip does not slide along the tool face but leaves under an angle of slide deformations $\phi$ in a form of little continous elements. That is why classical knowledge about chip creation, well-known from steel machining, cannot be used.

\section{References}

[1] FOUSOVA, M., VOJTECH, D. (2018). Thermal Treatment of 3D-printed Titanium Alloy. Manufacturing Technology, Vol.18, April 2018.

[2] BUMBALEK, B., BUMBALEK, Z. (2008). Surface Layer Properties of Titanium Alloys Ti16A14V, Ti7A13, 3MoO3Si ofter Milling and
Grinding Operation and Their Influence on the Fatique. Manufacturing Technology, 2008, Vol VIII, pp 40-46

[3] CZAN, A. et al. (2013). Studying og Cutting Zone When Finishing Titanium Alloy Application of Multificaction Measuring System. Manufacturing Technology. December 2013, Vol. 13, No.4, ISSN 1213-2489

[4] FOUSOVA, M., VOJTECH, D. (2018). Possibilities of Electron BEAm Melding Technology Titanium Processing. Manufacturing Technology, September 2018, Vol.18.

[5] JAROLIMOVÁ, P., JOSKA, L., HYBAČEK, V. (2018). TiAl4V Nanotubes Filled with Silver Nanoparticles as a Possible Antibacterial Surface fr Implants. Manufacturing Technology, June 2018, Vol. 18.

[6] KARASEVSKAYA, O. P. et al. (2003). Deformation behovior of beta titanium alloys, Materials Science and Engineering, 2003, Vol. 354, pp. 121123. Titanium a technical guide

[7] KOMANDURI, R. (1999). Some Classification on the Mechanics of Chip Formation of Titanium Alloys. In: $2^{\text {nd }}$ Int. Conference on High Speed Machining. Darmstadt, 1999, pp. 21-28

[8] KNAISLOVÁ, A., NOVÁK, P., PRŮŠA, F., KOPEČEK, J. (2018). Microstructure of TiAl15Si Alloy Prepared by Powder Mettalurgy Manufacturing Technology, September 2018, Vol.18.

[9] NOVAKOVA, L., HOMOLA, P., KAFKA, V. (2012). Microstructure Analysis of Titanium Alloys after Deformation by means of Asymmetric Ineremental Sheet Forming. Manufacturing Technology, 2012, No. 13, Vol 12, pp. 201-206.

[10] PRUCHOVA, E., KOSOVÁ, M, JAROLIMOVÁ, P., JOSKA, L., HYBAČEK, V. (2018). Ti6Al4V Nanotubes Fillet with Silver Nanoparticles as a Possible Antibacterial Surface for Implentants. Manufacturing Technology, June 2018, Vol. 18.

[11] VASILKO, K. (2001). Obrábanie titánu a jeho zliatin. FVT TU v Košiciach, 2001, ISBN 807099683-8

[12] WAISS, I., SEMIATIN, S, L. (1998). Thermomechanical processing of beta titanium. Science and Engineering, 1998, Vol. 243, pp. 46-65 